JOEAI (Journal of Education and Instruction)

Volume 2, Nomor 2, Desember 2019

e-ISSN : 2614-8617

p-ISSN : 2620-7346

DOI: https://doi.org/10.31539/joeai.v2i2.810

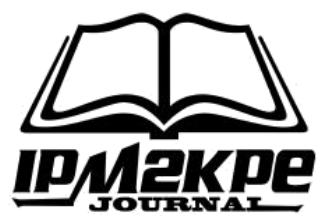

\title{
PEMANFAATAN YOUTUBE SEBAGAI SUMBER BELAJAR FISIKA
}

\author{
Elce Purwandari
}

Institut Agama Islam Al Azhaar Lubuklinggau

purwandari.elce@gmail.com

\begin{abstract}
ABSTRAK
Tujuan penelitian ini adalah untuk mengetahui pemanfaatan YouTube sebagai sumber belajar fisika siswa Sekolah Menengah Atas (SMA) Kecamatan Lubuklinggau Timur 1. Metode, penelitian ini merupakan penelitian survei eksplorasi, yang menggunakan kuisioner sebagai instrumen pengumpulan data dan teknik analisis data secara statistik deskriptif. Sampel dalam penelitian ini sebanyak 294 responden, sampel diambil dengan teknik accidental sampling. Hasil Penelitian, lebih dari setengah responden memanfaatkan YouTube sebagai sumber belajar dalam pembelajaran Fisika, dengan rincian 66\% menggunakan YouTube sebagai sumber belajar tambahan, $82 \%$ menggunakan YouTube untuk penyelesaian tugas dan $72 \%$ menggunakan YouTube sebagai sarana hiburan dan informasi. Simpulan, saat ini YouTube menjadi salah satu media alternatif yang banyak digunakan oleh sebagian besar siswa sebagai sumber belajar tambahan, membantu penyelesaian tugas dan sebagai sarana informasi serta hiburan yang juga didukung oleh penyediaan fasilitas internet oleh sekolah.
\end{abstract}

Kata Kunci: Fisika, Sumber Belajar dan YouTube

\section{ABSTRACT}

The purpose of this study was to determine the use of YouTube as a source of physics learning for high school (SMA) students in Lubuklinggau Timur District 1. The method, this research was an exploratory survey research, which used questionnaires as instruments for data collection and descriptive statistical data analysis techniques. The sample in this study were 294 respondents, the sample was taken by accidental sampling technique. Research results, more than half of respondents use YouTube as a learning resource in learning Physics, with details $66 \%$ using YouTube as an additional learning source, $82 \%$ uses YouTube for task completion and $72 \%$ uses YouTube as a means of entertainment and information. Conclusion, YouTube is currently one of the alternative media that is widely used by most students as an additional learning resource, helping with task completion and as a means of information and entertainment which is also supported by the provision of internet facilities by schools.

Keywords: Learning Resources, Physics and YouTube

\section{PENDAHULUAN}

Data pada tahun 2019 menunjukkan bahwa 56\% populasi atau 150 juta masyarakat di indonesia adalah pengguna internet dan aktif sebagai pengguna media sosial (Hootsuite, 2019). Seiring dengan hal tersebut, internet dan media sosial dapat dimanfaatkan dalam bidang pendidikan dengan cara memanfaatkan 
pembelajaran yang dilakukan secara online. Pembelajaran secara online dapat membuat peserta didik lebih mandiri (Delent, et al, 2014). Self-Regulated Learning atau kemandirian belajar adalah sikap untuk tidak bergantung kepada orang lain dalam kegiaan belajar, disertai gigih dalam usaha, bebas menentukan pilihan sendiri, memiliki inisiatif, bertindak secara efektif terhadap lingkungannya, serta konsekuen dalam mencapai tujuan yang diharapkan (Aziz \& Basry, 2017).

Diperlukan sumber belajar secara online yang berupa e-learning untuk menunjang kemandirian belajar peserta didik. Jika dibandingkan dengan metode pembelajaran tradisional, pemanfaatan E-learning memiliki banyak keunggulan (Ojeaga \& Igbinedion, 2012). Dalam pembelajaran fisika, materi yang diajarkan bukan hanya berupa pengetahuan, dan penyelesaian masalah berupa soal tes, namun juga ada penjelasan konsep melalui percobaan yang jika harus di praktekkan semuanya melalui praktikum tentu membutuhkan biaya dalam pengadaan alat dan bahan praktikum, bahkan ada beberapa konsep berkenaan dengan antariksa yang hanya bisa dipenuhi melalui video simulasi. Berdasarkan hal tersebut, e-learning dalam pembelajaran fisika berupa video pembelajaran yang dapat di akses melalui internet agar dapat menjadi sumber belajar fisika yang dapat dipelajari peserta didik secara online.

Salah satu penyedia website video-sharing yang mengizinkan pengguna untuk mengunggah, menonton, dan berbagi video adalah YouTube (Alwehaibi, 2015). Hal ini sejalan dengan Platform media sosial yang paling aktif di akses oleh pengguna internet di Indonesia adalah YouTube dengan persentase tertinggi sebesar 88\% (Hootsuite, 2019). Pengguna internet tersebut berada pada usia 16-64 tahun. Fleck dkk (2014) menyatakan YouTube merupakan tempat dimana setiap pengguna dapat berbagi video secara gratis dan disaksikan jutaan penonton setiap hari.

YouTube pertama kali diluncurkan tahun 2005 dan sejak saat itu tingkat kepopulerannya semakin memuncak sebagai website video-sharing. YouTube terus berinovasi hal ini terlihat dari fitur baru yang ada di YouTube seperti download video. Fitur download membuat video yang kita telah download tetap bisa dinikmati dalam keadaan offline. Banyak penelitian yang membuktikan bahwa YouTube berguna untuk berbagai spesialisasi (Sorenson, et al, 2014).

Penggunaan YouTube dalam dunia pendidikan bukanlah hal yang baru. Menurut Fleck, et al (2014) YouTube sebagai alat pendidikan melahirkan perhatian yang besar untuk menciptakan praktek-praktek pendidikan terbaik. Dalam pendidikan, YouTube dapat digunakan untuk mengilustrasikan konten subjek, melibatkan peserta didik dalam mencari informasi untuk suatu proyek, dan menginspirasi metode pengajaran yang inovatif (Agazio \& Buckley 2009). Memanfaatkan YouTube dalam pendidikan dapat membantu peserta didik dalam memperoleh pembelajaran dan pengalaman yang baru dalam menggunakan teknologi. 


\section{METODE PENELITIAN}

Metode penelitian yang digunakan yaitu survei dengan tujuan eksplorasi. Penelitian survei dilakukan bertujuan untuk memperoleh informasi tentang responden sebagai sampel penelitian yang mewakili penduduk dalam memanfaatkan YouTube sebagai sumber belajar fisika di Sekolah Menengah Atas (SMA) di Kecamatan Lubuklinggau Timur I, Kota Lubuklinggau. Penelitian ini memiliki sampel sebanyak 294 responden yang merupakan peserta didik SMA di Kecamatan Lubuklinggau Timur I, Kota Lubuklinggau. Pengambilan sampel dilakukan dengan menggunakan rumus Slovin (Mundir, 2014).

$$
n=\frac{N}{1+N e^{2}}
$$

dimana,

$\mathrm{n}=$ Jumlah Sampel

$\mathrm{N}=$ Jumlah Seluruh Populasi

$\mathrm{e}=$ Toleransi Error (batas akurasi,

batas signifikan seperti $1 \%$,

$5 \%$, atau $10 \%$ )

Teknik pengumpulan data yang digunakan dalam penelitian ini adalah kuesioner yang berisi daftar pertanyaan atau pernyataan yang digunakan oleh peneliti untuk mengum/pulkan data dari responden, yang kemudian data dianalisis menggunakan statistik deskriptif. Analisis statistik deskriptif adalah angka yang meringkas data dengan tujuan menggambarkan apa yang terjadi dalam sampel (Thompson, 2009).

\section{HASIL DAN PEMBAHASAN}

Siswa SMA di Kecamatan Lubuklinggau Timur I, umumnya akrab dengan YouTube. Pemanfaatan YouTube sebagai sumber belajar dalam penelitian ini dibagi menjadi tiga kategori, yaitu (1) YouTube sebagai bahan informasi pembelajaran, (2) kemudahan belajar, dan (3) faktor pendukung pemanfaatan YouTube. Kuesioner yang telah diisi oleh responden kemudian diubah dengan teknik statistik dalam bentuk persentase, adapun rumusnya sebagai berikut (Bungin, 2010).

$$
P=\frac{f}{n} x 100 \%
$$

dimana,

$\mathrm{P}=$ Persentase sumber daya

$\mathrm{f}=$ Frekuensi masing-masing jawaban yang dipilih

$\mathrm{N}=$ Jumlah total

Persentase untuk setiap kemungkinan jawaban Diperoleh dari membagi frekuensi yang Diperoleh dengan jumlah sampel Kemudian dikalikan dengan $100 \%$ (ketentuan). 
Kemudian persentase yang diperoleh diterjemahkan ke dalam tujuh kategori seperti yang ditunjukkan pada tabel 1 di bawah ini.

Tabel 1.

Kategori Persentase

\begin{tabular}{cc}
\hline Persentase & Kategori \\
\hline $0-1 \%$ & Tidak ada \\
$2 \%-25 \%$ & Persentase kecil \\
$26 \%-49 \%$ & Kurang dari setengah \\
$50 \%$ & Setengah \\
$51 \%-75 \%$ & Lebih dari setengah \\
$76 \%-99 \%$ & Sebagian besar \\
\hline $100 \%$ & Total \\
\hline
\end{tabular}

Sumber: Bungin (2010)

Berdasarkan penelitian survey dan perhitungan yang telah dilakukan, maka diperoleh hasil penelitian data seperti tercantum dalam tabel dibawah ini :

Tabel 2.

YouTube sebagai bahan informasi pembelajaran

\begin{tabular}{llll}
\hline No. & Aspek & Persentase & Ket \\
\hline 1. & $\begin{array}{l}\text { YouTube sebagai sumber belajar } \\
\text { tambahan untuk memperluas wawasan }\end{array}$ & $66 \%$ & $\begin{array}{l}\text { Lebih dari } \\
\text { setengah }\end{array}$ \\
2. $\quad \begin{array}{l}\text { YouTube sebagai sumber belajar } \\
\text { tambahan untuk menyelesaikan tugas }\end{array}$ & $82 \%$ & $\begin{array}{l}\text { Sebagian } \\
\text { besar }\end{array}$ \\
3. $\quad \begin{array}{l}\text { YouTube untuk mencari informasi atau } \\
\text { subyek berita sebagai sarana hiburan }\end{array}$ & $71 \%$ & $\begin{array}{l}\text { Lebih dari } \\
\text { setengah }\end{array}$ \\
\hline
\end{tabular}

Sumber: data primer diproses pada tahun 2019

Hasil penelitian menunjukkan bahwa $66 \%$ responden menyatakan bahwa lebih dari setengah peserta didik SMA di Kecamatan Lubuklinggau Timur I menggunakan YouTube sebagai sumber belajar tambahan untuk menambah wawasan, sedangkan yang lainnya sudah cukup menggunakan text book atau lainnya sebagai sumber belajar.

Tabel 3.

Kemudahan penggunaan YouTube untuk belajar

\begin{tabular}{clcc}
\hline No. & \multicolumn{1}{c}{ Aspek } & Persentase & Ket \\
\hline 1. & $\begin{array}{l}\text { Kemudahan dalam memahami materi } \\
\text { pembelajaran fisika }\end{array}$ & $77 \%$ & $\begin{array}{c}\text { Sebagian } \\
\text { besar }\end{array}$ \\
2. & Kemudahan akses YouTube & $75 \%$ & $\begin{array}{c}\text { Lebih dari } \\
\text { setengah }\end{array}$ \\
\hline
\end{tabular}

Sumber: data primer diproses pada 2019 
Pemanfaatan YouTube memberikan kemudahan bagi peserta didik dalam memahami materi pembelajaran Fisika dimana 77\%, menyatakan dengan adanya video dari YouTube dapat membantu sebagian besar peserta didik dalam menangani kesulitan belajarnya,

Tabel 4.

Faktor-faktor yang mendukung penggunaan YouTube

\begin{tabular}{|c|c|c|c|}
\hline No. & Aspek & Persentase & Ket \\
\hline 1. & $\begin{array}{l}\text { Fasilitas } \\
\text { Sekolah }\end{array}$ & $85 \%$ & $\begin{array}{c}\text { Sebagian } \\
\text { besar }\end{array}$ \\
\hline 2. & Peran Guru & $73 \%$ & $\begin{array}{c}\text { Lebih dari } \\
\text { setengah }\end{array}$ \\
\hline
\end{tabular}

Fasilitas sekolah merupakan salah satu sarana pendukung dalam memanfaatkan YouTube dalam proses pembelajaran, hal ini terlihat dari hasil persentase sebesar $85 \%$ yang berarti bahwa sebagian besar sekolah telah menyediakan koneksi free wifi, laboratorium komputer dan Liquid Crystal Display (LCD) yang dapat dimanfaatkan oleh guru dan peserta didik dalam menunjang proses pembelajaran.

Secara garis besar, hasil penelitian menunjukkan bahwa 66,\% responden telah memanfaatkan YouTube sebagai sarana mencari informasi untuk menambah wawasan, $82 \%$ sebagai sumber belajar tambahan untuk menyelesaikan tugas dan $71 \%$ sebagai sarana hiburan untuk mendapatkan informasi yang terkini, selain itu $77 \%$ responden menyatakan bahwa pemanfaatan YouTube membantu mereka dalam memahami materi pembelajaran yang sulit dipahami karena kemudahan dalam mengakses, dimana $75 \%$ responden menyatakan bahwa YouTube dapat diakses kapan saja dan dimana saja secara gratis. Selain itu, sekolah dan guru juga memberikan dukungan dan fasilitas kepada peserta didik untuk memanfaatkan YouTube dalam proses pembelajaran. Hal ini terlihat dari $85 \%$ sekolah memiliki koneksi free wifi, laboratorium komputer dan Liquid Crystal Display (LCD) untuk menunjang proses pembelajaran dan $73 \%$ responden menyatakan lebih dari setengahnya guru telah menggunakan YouTube untuk menyampaikan materi pembelajaran dan mengarahkan peserta didik untuk mengakses YouTube sebagai sumber belajar dalam menambah wawasan dan membantu menyelesaikan tugas.

\section{Youtube Bahan Informasi Pembelajaran}

Pemanfaatan YouTube yang dilakukan untuk membantu peserta didik dalam menyelesaikan tugas ditunjukkan dengan hasil persentase sebesar $82 \%$, yang berarti bahwa sebagian besar peserta didik memanfaatkan YouTube sebagai sumber belajar tambahan untuk membantu dalam menyelesaikan tugas-tugas mata pelajaran fisika. Selain sebagai sumber belajar, pemanfaatan YouTube juga 
digunakan sebagai sarana hiburan bagi peserta didik, hal ini terlihat dari persentase sebesar $71 \%$ di mana lebih dari setengahnya, peserta didik memanfaatkan YouTube untuk mencari informasi atau berita di luar dari mata pelajaran fisika. Hal ini dilakukan peserta didik untuk mendapatkan informasi terkini agar tidak ketinggalan zaman.

Hal ini sejalan dengan Szeto \& Cheng (2014) yang menjaskan bahwa YouTube dapat membantu siswa dalam mencari topik yang menarik dan memberikan lingkungan untuk mengajarkan perancah yang memberikan motivasi kepada siswa dan konteks khusus untuk memahami pengetahuan baru, yang akan membantu mereka dalam mempelajari pelajaran selanjutnya.

\section{Youtube sebagai pembantu belajar siswa}

Pemanfaatan YouTube memberikan kemudahan bagi peserta didik dalam memahami materi pembelajaran Fisika dimana 77\%, menyatakan dengan adanya video dari YouTube dapat membantu sebagian besar peserta didik dalam menangani kesulitan belajarnya, karena dengan memanfaatkan YouTube mereka dapat melihat contoh secara langsung melalui video yang ada di YouTube. Szeto \& Cheng (2014) menjelaskan bahwa YouTube dapat membantu dan memotivasi peserta didik dalam belajar yang tidak hanya terfokus hanya pada ruang kelas saja. Hal ini dapat dilihat dari hasil jawaban responden mengenai kemudahan dalam mengakses YouTube dengan hasil persentase sebesar $75 \%$ responden mengakui bahwa mengakses YouTube sangatlah mudah dilakukan kapan saja dan dimana saja serta tidak berbayar, dengan syarat koneksi jaringan internet yang baik.

\section{Faktor-faktor yang mendukung penggunaan YouTube}

Fasilitas sekolah merupakan salah satu sarana pendukung dalam memanfaatkan YouTube dalam proses pembelajaran, hal ini terlihat dari hasil persentase sebesar 85\% yang berarti bahwa sebagian besar sekolah telah menyediakan koneksi free wifi, laboratorium komputer dan Liquid Crystal Display (LCD) yang dapat dimanfaatkan oleh guru dan peserta didik dalam menunjang proses pembelajaran.

Sebagain besar sekolah telah memiliki koneksi free wifi, meskipun jaringan wifi yang tersedia masih tergolong minim, hal ini dikarenakan koneksi free wifi yang tersedia hanya dapat dimanfaatkan di lokasi tertentu, seperti di ruang guru, ruang laboratorium dan di beberapa ruang kelas saja. Selain fasilitas sekolah, dukungan guru juga merupakan faktor pendukung dalam memanfaatkan YouTube, dimana $73 \%$ guru telah menggunakan video dari YouTube untuk menyajikan materi pembelajaran dan mengarahkan peserta didik untuk mendownload video dari YouTube sebagai sumber belajar tambahan untuk menambah wawasan dan menyelesaikan tugas.

Szeto \& Cheng (2014) menjelaskan bahwa bagi guru YouTube menjadi sumber belajar yang baik digunakan untuk siswa dalam memperoleh pengetahuan, 
peran guru dalam hal ini sebagai fasilitator untuk membimbing siswa dalam proses memperoleh pengetahuan tersebut.

Keterbatasan pertama dalam penelitian ini adalah bahwa kuesioner hanya ditulis dalam bahasa Indonesia. Namun, instruktur/peneliti hadir untuk membantu menjelaskan masalah yang mungkin dialami siswa. Kedua, survei yang dilakukan mungkin telah menyebabkan peserta didik melebih-lebihkan jawaban mereka, untuk mengatasi hal ini, para siswa diberitahu bahwa hasil survei itu harus dikumpulkan dan tidak akan mempengaruhi nilai akhir mereka. Kekurangan lainnya adalah ukuran sampel yang relatif kecil, terutama dalam hal siswa perempuan. Dengan demikian, sulit untuk membuat perbandingan gender.

Kelebihan dari penelitian ini fakta bahwa sampel berasal dari satuan pendidikan yang berbeda bahwa hasil dapat diekstrapolasi ke populasi siswa umum. Mengenai penelitian selanjutnya, direkomendasikan agar penelitian menggunakan ukuran sampel yang lebih besar dengan siswa dari berbagai satuan pendidikan. Selanjutnya, dapat membuat penelitian perbandingan antara kurikulum dengan dan tanpa YouTube digunakan sebagai bahan tambahan untuk membantu menilai dampak YouTube pada pelajaran fisika.

\section{SIMPULAN}

Saat ini YouTube menjadi salah satu media alternative yang banyak digunakan oleh sebagian besar siswa sebagai sumber belajar tambahan, membantu penyelesaian tugas dan sebagai sarana informasi serta hiburan yang juga didukung oleh penyediaan fasilitas internet oleh sekolah. Guru di sekolah sudah menggunakan YouTube untuk menyampaikan materi pembelajaran dan mengarahkan peserta didik untuk mengakses YouTube sebagai sumber belajar dalam menambah wawasan dan membantu menyelesaikan tugas.

\section{DAFTAR PUSTAKA}

Agazio, J., \& Buckley, K. M. (2009). An Untapped Resource: Using YouTube in Nursing education. Nurse educator, 34(1); 23-28.

Alwehaibi, H.O. (2015). The Impact of UsingYouTube In EFL Classroom on Enhancing EFL Students' Content Learning., Journal of College Teaching \& Learning, 12(2); 121-126.

Aziz, A., \& Basry. (2017). Hubungan Antara Kompetensi Guru dan Kepercayaan Diri Dengan Kemandirian peserta didik SMPN 2 Pangkalan Susu. Jurnal Psychomutiara, 1(1); 15-29.

Burhan, B. (2010). Metode Penelitian Kualitatif. Rajawali Pers: Jakarta.

Delent, E., Liew, J., \& Willson, V. (2014). Effects of Interactivity and Instructional Scaffolding on Learning: Selfregulation in Online Video-based Environments., Computers \& Education, 78;312- 320.

Fleck, B.K.B., Beckman, L.M., Stern, J.L., \& Hussey H.D. (2014). YouTube in the Classroom: Helpful Tips and Student Perceptions, The Journal of Effective Teaching, 14(3); 21-37. 
Hootsuite. (2019). Digital 2019, Global Digital year book. https://hootsuite.com/pages/digital-in-2019\#accordion-115547Diakses tanggal 24 Juli 2019.

Ojeaga I. J., \& Igbinedion, V. I. (2012). Potentials of E-learning as a Study Tool in Business Education in Nigerian Schools, International Education Studies, 5(5); 218-215.

Sorenson, J. A., Pusz, M. D., \& Brietzke, S. E. (2014). YouTube As An Information Source For Pediatric Adenotonsillectomy And Ear Tube Surgery, International Journal of Pediatric Otorhinolaryngology, 78, 65-70.

Szeto, E., and Cheng, A. Y. (2014). Exploring The Usage of ICT and YouTube for Teaching: A Study of Pre-Service Teachers in Hong Kong. The Asia-Pacific Education Researcher, 23(1).

Thompson, C. B. (2009). Descriptive Data Analysis. Air Medical Journal, 28(2). 